\title{
Contractor Selection Criteria in Ghanaian Construction Industry: Benefits and Challenges
}

\author{
Daniel Nii Ayeh Ayettey'1, Humphrey Danso ${ }^{2 *}$ \\ ${ }^{1}$ Department of Works, Asunafo North Municipal Assembly, Goaso, Ghana \\ ${ }^{2}$ Department of Construction and Wood Technology, University of Education Winneba, Kumasi, Ghana \\ Email: *hdanso@uew.edu.gh, *dansohumphrey@yahoo.co.uk
}

How to cite this paper: Ayettey, D.N.A. and Danso, H. (2018) Contractor Selection Criteria in Ghanaian Construction Industry: Benefits and Challenges. Journal of Building Construction and Planning Research, 6, 278-297.

https://doi.org/10.4236/jbcpr.2018.64019

Received: September 13, 2018

Accepted: November 30, 2018

Published: December 3, 2018

Copyright $\odot 2018$ by authors and Scientific Research Publishing Inc. This work is licensed under the Creative Commons Attribution International License (CC BY 4.0).

http://creativecommons.org/licenses/by/4.0/

\begin{abstract}
Selecting a contractor for construction project is a difficult decision to be taken by a client because it may lead to construction delivery problems or successful delivery of the project. This study, therefore, investigated the contractor selection criteria in the Ghanaian construction industry, considering the benefits and challenges. A quantitative research method was adopted in this study through the use of a questionnaire. The target population for the study consisted of registered contractors and consultants in the Ashanti and Brong-Ahafo regions of Ghana. It was found that though the construction professionals are well vested with the prequalification selection criteria that are being used within the Ghanaian construction industry, they were not familiar with multi-criterial section methods. It was also found that the benefits of the contractor selection criteria include: enabling the client to select contractors who are performers for the project, saving the project owner a lot of time, minimizing the possibility of contractor default, and facilitating the achievement of project success and the objectives within the scheduled time. Furthermore, excessive cost and time overrun, poor quality standard, imprecise assessments due to lack of information, criteria being very complex and difficult to apply in practice, among others were identified as the challenges to the contractor selection criteria in Ghanaian construction industry. The study recommends for further studies to determine the impact of the identified challenges on construction projects, and ways to minimize the challenges.
\end{abstract}

\section{Keywords}

Contractor Selection Criteria, Construction Industry, Multi-Criterial Section Methods, Prequalification Selection Criteria 


\section{Introduction}

Selection of a contractor for the construction project is a complicated and ambiguous process and relies mostly on the appropriateness of the tender requirement [1] [2]. Studies on contractors' selection can be traced back to the early years of the 1960s and hitherto different selection criteria have been prescribed to be used for the selecting of the most capable contractor, ranging from linear programming to nonlinear programming [3]. The growing numbers of contractor selection criterion signify how immensely the construction industry contributed to the economic growth of any country. Selecting the most capable contractor for a construction project is an important decision for client and project managers [4]. The process of choosing a capable contractor is such a difficult decision to be taken by a client due to the fact that choosing an inappropriate contractor would certainly lead to cost overturns, delays and substandard work. The only way to avoid this is to make sure that the contractor is able to execute the project and comply with contract specifications which indicate client's needs [5] [6].

Contractor selection criteria can be described as the set of requisite indicators that entails series of decision attributes that guide project owner's to select the capable contractor out of the lot for a given construction project [7]. It can also be described as a set of predetermined criteria that assist a project owner to select a capable contractor for a given project. Skibniewski and Chao [8] described contractor selection criteria as a decision-making process that involves the development and wide consideration of all relevant and sufficient decision making criteria used to assess a contractors' abilities to fulfill the outcomes of project (i.e. completing it on the scheduled time, within the right cost and at the right quality). The purpose of the contractor selection criteria is to lower the risks associated with projects, maximize the overall value to the project owner and consequently build close and long-term relationships between members of the project [9].

Notwithstanding, the associated failures of the various selection criteria within the global context, in the scope of Ghana the story are fairly not different. In Ghana, many contractors have equally shown strong public outcry about how the bidding processes are being run by the procurement agencies. Some contractors have complained publicly that during the bidding processes the final bid most often times goes to the lowest bidder. In most developing countries the available evidence suggests that the contractor selection processes are often times taken for granted in the construction procurement supply chain [7] [10]. Even though there has been common agreement the world over that lower price should not be the most dominant evaluation factor during the selection process [3] yet it appears that the selection of contractors in developing countries such as Ghana is often based on the criterion of least bid amount or cost [7]. In most often times project owners largely perceived that project success could only be ensured by accepting the lowest priced tender [11]. A lower bid amount may seem 
to be attractive to the project owner at the tender stage hence resulting to instances where project managers may be forced to overlook other key criteria that should equally be given more consideration in the selection process [12]. This situation in the selecting processes often results in poor construction performance, cost overruns, project completion delays, abandonment of projects, among others.

Salama et al. [4] investigated the criteria for contractors' selection and bid evaluation in Egypt, and also provided critical discussion on the laws and regulations in Egypt, and concluded with a list of recommendations that aims at guiding practitioners and planning authorities to enhance the current practice. Ale$\mathrm{mu}$ [13] assessed the contractors' qualification criteria in Ethiopia federal road project tender practices and revealed that qualification criteria used are not following any standard and did not consider the size of projects in the subject and that the qualification criteria are wide open to be manipulated by the employer. Singh and Tiong [14] studied the contractor selection criteria by investigating the opinions of Singapore construction practitioners. Their results reflected that though the respondents share some degree of commonality with respect to the relevance of the contractor selection criteria, their decision-making preferences during the selection process are context specific. Zavadskas et al. [15] examined the contractor selection of construction in a competitive environment in Lithuania and found that the selection of contractor can be with different risk level, and therefore, Hodges-Lehmann rule will allow stakeholders to select contractor taking into account different risk levels. From the foregoing, it is clear that studies of contractor selection have been conducted in different countries with different findings. There is, therefore, the need to examine the contractor selection criteria in the Ghanaian construction industry. This study, therefore, investigates the contractor selection criteria in the Ghanaian construction industry. It seeks to identify the prequalification selection criteria, multi-criteria selection methods, benefits and challenges of contractor selection in the Ghanaian construction industry. The study contributes to knowledge in the area of contractor selection in a developing country context.

\section{Literature Review}

This section of the paper reviews some of the current investigations conducted on the contractor selection criteria in the construction industry. Construction is a risk inclined, unpredictable and consequently operates in an uncertain environment where two projects are hardly ever the same [3]. As such, contractor none performance is always possible, even in instances where able and efficient contractors are selected for a construction project [16]. For this reason, project owners and clients look for ways to lessen the risk of contractor none performance hence relying on a predetermined set of criteria to aid project owners to choose the best contractor out of the lot for a given project [3]. According to Ramón and Cristóbal [17] there has been an array of selection criteria, namely; 
lowest-price wins, subjective judgment and multi-criteria selection approach used in selecting contractors for construction projects.

The upsurge in the identification of the varying degrees of methodologies that can be used for the selection processes, one is still required to formulate an objective function before the commencement of the selection exercise [18]. During the prequalification process, the contractors rank order is prepared according to factors such as experience, financial standing, technical expertise, track record etc. Then, a limited number of the best contractors are invited to tender. Their tenders are then evaluated on the basis of economic criteria and, in some projects, on the basis of technical criteria [19]. Contract selection based on the lowest price criterion may contribute to the imperfect competition in the market by means of artificially depressing the prices [1]. As a result of this process, some additional unforeseen cost of the investment may occur [1]. An example is when a contractor decides to walk off site due to a bankruptcy, which incurs some additional cost including possible changes to the project and the repeated process of appointing a new contractor. It requires knowledge and experience from the project manager in order to use the appropriate criteria to ensure the selection of the most suitable contractor who will be more prepared in terms of technical and financial for the project [20].

The construction project is a complicated and ambiguous process and relies mostly on the appropriateness of the tender requirement, where all the requirements and necessity of the tender must be clearly defined [1] [2]. Unfinished description of tender requirements usually aggravates the risk that the selected contractor could become incapable to meet the desires of the projects [21]. Hence, a tender is a submission made by a prospective supplier in response to an invitation to tender. It makes an offer for the supply of goods or services.

One of the key benefits associated with prequalification contractor selection criteria is that it enables project owners to screen and shortlist the possible contractors who may have the ability to undertake the project corroborated [22]. Prequalification selection criteria allow a client to choose the most appropriate contractor [22] [23]. Also, in the study of Olatunji [24] it became evident that through prequalification selection methods, projects owners within Nigeria were able to select high performing contractors for a given project. Morote and Vila [25] shared similar view when their study results established that the application of multi-criteria selection methods helped clients and decision makers to minimize and exclude incompetent, unsuccessful contractors from the bidding process. Within the context of Saudi Arabia, Ramani [26] study results showed that through the use of prequalification criteria, project owners were able to reduce subjectivity that was found to be characterized with the previous selection methods. Holt et al. [27] also found that through contractor selection method, public clients were able to select a qualified contractor aiding the client to avoid project delay, failure, misuse of fund and abandonment.

Ogunsemi and Aje [28] affirmed Holt and colleagues study results in their 
study which the application of prequalification contractor selection method led to massive project success in Nigeria. In the study of Topcu [11] it was established that through contractor selection methods, clients were able to avoid the selection of unprepared contractors. It also protected bidders from being given projects they may not be able to execute within their abilities and competencies. It can also reduce the percentage of project risk [11]. It can speed up the process of evaluation and contract to award and controls the number of bidders who have limited financial resources or experience from biding in the construction project. In the studies of Huang [29] and Al-Harbi [30] the authors identified that through the application of contractor selection criteria, project owners were able to ensure successful and efficient use of their money by ensuring that only competent contractors were selected to execute the project. Huang [29] established that because contractor selection criteria help clients to select the efficient, capable and skilled candidate out of the lot, it guarantees the completion of work within the specified cost and time.

Kog and Yaman [5] affirmed in their work when their findings show that contractor selection criteria give a chance to the client to evaluate the candidate and potential thoroughly before recruiting him for the job, as well as facilitates the achievement of the optimum result in terms of cost, time and quality projects. Darvish et al. [31] found in their study that contractor selection criteria helped project owners to reduce the opportunity of contractor default in bidding and restrict the number of eligible contractors involved. Bendana et al. [32] assert that contractor selection criteria enabled clients to ascertain a contractor's suitability for undertaking the designs in a specific environment. Fong and Choi [33] confirmed that the contractor selection model gives clients the flexibility to add or reduce the elements of a possible problem hierarchy within a development project.

Several construction projects experience time and cost overruns due to the wrong choice of a contractor or a selection criterion [34] [35]. This situation becomes more apparent in the government contract in which contracts are awarded to the lowest bidder not necessarily by the responsive bidder. According to Nkanta et al. [34], prequalification criteria which strictly look at contractor's past experience will demand evidence in the forms of presentation of recommendation letters from previous clients and certificates of practical completion of similar jobs executed in the past three to five years. Olatunji [24] argues that one of the key challenges associated with the application of this criterion in Nigeria was that most contractors with excellent performance records were found not have impressive scores during assessments, largely because most candidates within Nigeria did not have a good understanding about how to present their evidence or recording in the proper format. This suggests that an improper presentation of evidence to prove a contractor credibility during the assessment process is likely to make a capable contractor appear incapable hence making the contractor ignored from the selection process. Another difficulty 
associated with the contractor prequalification criteria is that its application is found to involve much uncertainty and incomplete compilation of information, therefore making it very difficult to ascertain the objectiveness of its decision outcomes [36]. The authors again added that these substantial uncertainties and subjectivities have hampered the applicability of many prequalification selection criteria.

Conversely, El-Sawalhi et al. [12] posited that often times the prequalification selection contains risks inherited from different decision maker's opinion making results from its application very biased. Mahdi et al. [37] observed that with the prequalification selection criteria, contractors have to rely on their experience, skills, and relevant knowledge of the decision-maker (i.e. the client). Experience and knowledge of the relevant decision-makers differ from one to the other and there are no specific standards to ensure the quality of the selection process even when being made by knowledgeable and experienced decision-makers [37]. Another weakness associated with prequalification selection criteria is that it contains subjective judgment made by decision makers hence making its results highly unreliable [12]. Nkanta et al. [34] study revealed that the assessment of most of the prequalification criteria is informed from information provided by the contractor as well as additional evidence given on paper records. This, therefore, provides project owners and clients the avenue to evaluate the firm's capabilities on facts based on documents showing relevant past experience and peculiar reputation in similar projects. The challenge with this method is that due to the limited time required during the bidding process, project owners usually do not have the time and resources to confirm the state of some of the claims made or presented by a contractor. This implies that many firms can lay claim to a single individual, without his consent or to untraceable persons (dead, bankrupt, and illegal entities) as the technical members of their firm [34].

Elsayah [21] identified that the decision maker is required to have the extensive mathematical background, therefore making it hard to collect data on its assessment criteria as well as understand and even run the entire analysis. Therefore, as each multi-criteria selection technique has different properties suited for different types of problems, there is no simple answer as to which method to use for a particular problem. As such, weighting and scoring systems are critical in most multi-criteria selection technique. However, the processes of assessing weights and scores have been criticized as highly arbitrary and subjective and furthermore, the use of arbitrary weights in multi-attribute analysis and lack of a standard methodology increases the scope for misuse and deliberation [15]. Rikhtegar [38] asserts that another difficulty associated with multi-criteria selection method is that they are not able to handle the imprecise and ambiguous detail involved in real-life decision-making problems. Hence, the results associated with multi-criteria selection methods are found to be unrealistic leading to unreliable assessment. Moreover, since the estimates yielded multi-criteria selection methods do not always reflect the real situation, the outcome obtained may not 
be logical, with the values of one particular criterion largely differed from those of other criteria [39].

\section{Methodology}

The study adopted a descriptive research design through the use of questionnaires because it provided a more valid data taking into account the scope of the research [40]. The descriptive design was appropriate because it helps in the observance of the phenomenon in a completely natural and unchanged natural environment, as this study seeks to investigate the contractor selection criteria in Ghanaian construction industry. The target population for the study consisted of registered contractors with the Metropolitan, Municipal and District Assemblies (MMDAs), Ministry of Water Resources, Works and Housing. The others include members of the Association of Road Contractor of Ghana (ASROC), the Association of Building and Civil Engineering Contractors of Ghana (ABCECG) as well as consultants within the MMDAs and Architecture and Engineering Services Limited (AESL) in both Ashanti and Brong-Ahafo regions of Ghana. 350 contractors and consultants were identified to be in good standing, however, 172 were sampled based on Krejcie and Morgan [41] sampling table. Simple random sampling technique was used to select the respondents from the registered contractors and consultants. The selected registered contractors range from D1 to D4 as classified by the Ministry of Water Resource, Works and Housing and $\mathrm{K} 1$ to $\mathrm{K} 4$ contractors as classified by the Ministry of Roads and Transport [42]. The contractors in each of the category are further grouped into financial classes 1, 2, 3 and 4 based on their technical and managerial expertise, financial standing, previous performance, and equipment and plant holding [43].

Data was collected using a questionnaire consisting of both open-ended and closed-ended questions. Saunders et al. [44] explained that an open-ended questionnaire enables one to understand the relationships between variables, particularly those revealed through a descriptive study. The questionnaire was divided into four sections. The first section requested profiles of respondents. The second section elicited a response on the contractor selection criteria that are available in the Ghanaian context and the third section constituted questions on the challenges relating to the contractor selection criteria in Ghana. The fourth section focused on the benefits of the contractor selection criteria. A 4-point Likert scale (i.e. 1) never heard about the method, 2) not familiar with the method, 3) familiar with the method and 4) very familiar with the method) to elicit respondents' responses as to the degree of familiarity with the presented contractor selection criteria. However, with the second construct of the study thus, challenges associated with the contractor used within the Ghanaian context, the study used a 3-point Likert ( 1) to a low extent, 2) to a medium extent, 3) to a high extent) to elicit respondents' answers as to how the given problems were attributed to the contractor selection criteria. The next section thus, benefits of 
the contractor selection criteria the study employed a 5-point Likert scale (i.e. 1) strongly disagree, 2) disagree, 3) neutral, 4) agree and 5) strongly agree).

Construct validity was ensured by critically developing the indicators within the established theoretical framework. Cronbach alpha reliability test for the items was above the recommended 0.7 [45]. From Table 1, all of the constructs have item loadings higher than the recommended 0.70. Out of the 172 questionnaires administered, a total of 122 completed questionnaires were returned. Nonetheless, of these retrieved questionnaires, 104 were usable for analysis providing an effective response rate of $60.47 \%$. This response rate is considered

Table 1. Item loading, construct reliability.

\begin{tabular}{|c|c|c|c|}
\hline Dimension & Indicators & No. of items & Cronbach Alpha \\
\hline \multirow{6}{*}{$\begin{array}{l}\text { Contractor } \\
\text { prequalification } \\
\text { selection criteria }\end{array}$} & Financial stability evaluation & \multirow{6}{*}{6} & \multirow{6}{*}{0.953} \\
\hline & Management and technical ability evaluation & & \\
\hline & Contractor's experience evaluation & & \\
\hline & Contractor's nast performance & & \\
\hline & Plant and human resources evaluation & & \\
\hline & Health and safety and environmental measures & & \\
\hline \multirow{6}{*}{$\begin{array}{l}\text { Multi-criteria } \\
\text { methods }\end{array}$} & Multi-criteria utility theory (MUT) & \multirow{6}{*}{6} & \multirow{6}{*}{0.924} \\
\hline & Complex Proportional Assessment (COPRAS) & & \\
\hline & Evidential Reasoning (ER) & & \\
\hline & Analytic Network Process (ANP) & & \\
\hline & Program Evaluation and Review Technique (PERT) approach & & \\
\hline & Fuzzy Set Theory (FST) & & \\
\hline \multirow[t]{6}{*}{ Benefits } & Facilitate the achievement of project success and the objectives within the scheduled time & \multirow{6}{*}{6} & \multirow{6}{*}{0.980} \\
\hline & Reduce the associated project risk during the bidding and the construction processes & & \\
\hline & Maximize overall value to the project owner or client & & \\
\hline & Enable the client or project owner to select contractors who are performers for the project & & \\
\hline & Minimize the possibility of contractor default & & \\
\hline & Save the project owner a lot of time & & \\
\hline \multirow[t]{9}{*}{ Challenges } & Removal of effective and competent contractors & \multirow{9}{*}{9} & \multirow{9}{*}{0.923} \\
\hline & It leads to projects failure in terms of time delay & & \\
\hline & Poor quality standard & & \\
\hline & Some of the criteria are very complex and difficult to apply in practice & & \\
\hline & Excessive cost and time overrun & & \\
\hline & Substandard work & & \\
\hline & Imprecise assessments due to lack of information & & \\
\hline & Shortcomings in expertise in the application method & & \\
\hline & Disputes among contractors and clients & & \\
\hline
\end{tabular}


sufficient, according to Mugenda and Mugenda [46] a response rate of $50 \%$ is adequate for a study. The data collected were keyed into The IBM Statistical Package for Social Sciences (SPSS) version 20.0 and the result of the study was analysed on the basis of descriptive statistics. Mean score, standard deviation and frequencies were computed to find out the various contractor selection criteria that are being used within the country and likewise to its ability to select the best contractor for the job. One-sample t-test analysis was conducted to determine whether the respondents' ratings were significant or not at 0.05 significant level.

\section{Results and Discussion}

\subsection{Demographic Profile of Respondents}

The demographic profile of the respondents in Table 2 shows that 43 of the respondents, thus $41.35 \%$ were the consultants, whereas 61 (58.65\%) of the respondents were contractors. With respects to the consultants' professional field, $20(46.51 \%)$ were in the quantity surveying field, whereas $13(30.23 \%)$ and 10 (23.26\%) of the respondents belong to the engineering and construction technology fields respectively. The contractors' association fields indicate that 24 (39.34\%) of the respondents belonged to the Institute of Engineers and Technology

Table 2. Demographic profile of respondents.

\begin{tabular}{|c|c|c|c|}
\hline Demographic variable & Category & Frequency & Percentage \\
\hline \multirow{3}{*}{$\begin{array}{l}\text { Respondents } \\
\text { composition }\end{array}$} & Consultants & 43 & 41.35 \\
\hline & Contractors & 61 & 58.65 \\
\hline & Total & 104 & 100.00 \\
\hline \multirow{4}{*}{$\begin{array}{l}\text { Consultants' } \\
\text { professional field }\end{array}$} & Engineering & 13 & 30.23 \\
\hline & Quantity Surveying & 20 & 46.51 \\
\hline & Construction Technology & 10 & 23.26 \\
\hline & Total & 43 & 100.00 \\
\hline \multirow{7}{*}{$\begin{array}{l}\text { Contractors' association } \\
\text { fields }\end{array}$} & $\begin{array}{c}\text { Association of building and civil engineering } \\
\text { contractors of Ghana }\end{array}$ & 14 & 22.95 \\
\hline & Association of road contractors of Ghana & 6 & 9.84 \\
\hline & Institute of engineers and technology Ghana & 24 & 39.34 \\
\hline & Chartered Institute of building & 17 & 27.87 \\
\hline & Total & 61 & 100.00 \\
\hline & 1 - 5 years & 13 & 12.50 \\
\hline & $6-10$ years & 29 & 27.88 \\
\hline \multirow{4}{*}{$\begin{array}{l}\text { Work experience in the } \\
\text { construction industry }\end{array}$} & $11-15$ years & 36 & 34.62 \\
\hline & $16-20$ years & 18 & 17.31 \\
\hline & Over 20 years & 8 & 7.69 \\
\hline & Total & 104 & 100.00 \\
\hline
\end{tabular}


Ghana, 17 (27.87\%) and 14 (22.95\%) belong to the Chartered Institute of Building and Association of Building and Civil Engineering Contractors of Ghana respectively, with Association of Road Contractors of Ghana constituting 6 (9.84\%). In terms of working experience, 13 (12.50\%) have 1 - 5 years, 29 (27.88\%) have 6 10 years, $36(34.62 \%)$ have between $11-15$ years, 18 (17.31) have $16-20$ years, while $8(7.69 \%)$ have been working in the construction industry for over 20 years now.

\subsection{Prequalification Selection Criteria}

The purpose of this section was to ascertain the various contractor prequalification selection criteria that are being employed or used within the Ghanaian construction industry. Therefore, the study respondents were asked to indicate their level of familiarity as to whether these selection criteria have been applied to them in any projects they ever bided for. With a 4-point Likert scale response, the respondents rated their familiarity with the prequalification criteria. A significant level of 0.05 was pre-determined and a hypothesize mean of 2.5 was chosen as an indicator of acceptable rating the respondents' familiarity with the contractor selection criteria as measured by the questionnaire. The result in $\mathrm{Ta}$ ble 3 shows that all the items recorded values greater than the hypothesize mean of 2.5, which implies that the respondents rated these items between familiar and very familiar. It can be seen that "management and technical ability evaluation method" and "contractor's experience evaluation method" were the items highly rated by the respondents with each having a mean value of 3.80 . This was closely followed by "contractor's past performance method" with a mean value of 3.78 .

The least rated item "health and safety and environmental measures method" with mean values of 3.23 indicate clearly that the construction professionals are well vested with the prequalification selection criteria that are being employed or used within the Ghanaian construction industry. To determine whether the respondents' ratings were significant or not, one sample t-test analysis was conducted, and as can be seen in Table 3, all the items recorded values that are less than 0.05 which indicate that the respondents' ratings were significant. Findings

Table 3. Contractor prequalification selection criteria.

\begin{tabular}{|c|c|c|c|c|c|c|}
\hline \multirow{2}{*}{ Selection Criteria } & \multicolumn{2}{|c|}{ Descriptive } & \multicolumn{3}{|c|}{ One-sample t-test } & \multirow{2}{*}{ Remark } \\
\hline & Mean & Std. Dev. & $\mathrm{t}$ & Mean Diff. & Sig. (2-tailed) & \\
\hline Financial stability evaluation method & 3.77 & 0.421 & 17.199 & 0.773 & 0.00 & Very familiar \\
\hline Management and technical ability evaluation method & 3.80 & 0.406 & 18.394 & 0.795 & 0.00 & Very familiar \\
\hline Contractor's experience evaluation method & 3.80 & 0.406 & 18.394 & 0.795 & 0.00 & Very familiar \\
\hline Contractor's past performance method & 3.78 & 0.441 & 16.69 & 0.784 & 0.00 & Very familiar \\
\hline Plant and human resource evaluation method & 3.76 & 0.455 & 15.707 & 0.761 & 0.00 & Very familiar \\
\hline Health and safety and environmental measures method & 3.23 & 0.562 & 3.795 & 0.227 & 0.00 & Familiar \\
\hline
\end{tabular}

Sig. $\leq$ 0.05; Mean 1.0 to $1.44=$ not at all familiar; Mean 1.50 to $2.44=$ not familiar; Mean 2.5 to $3.44=$ familiar; Mean 3.44 to $4.0=$ very familiar. 
from this study are consistent with the earlier work of $\mathrm{Ng}$ and Skitmore [47] which in their study identified prequalification selection methods such as; financial stability, performance evaluation, health and safety evaluation and contractor's past performance as the most preferred prequalification criteria used by UK clients and consultants.

The findings from this study corroborate the works of Bubshalt and Al-Goball [48] and Monyane and Emuze [9] whom in their separate studies identified contractor past experience evaluation method as one of the key prequalification criteria used in the selection of contractors since it enables clients to assess whether a contractor has a fair understanding of the project at hand. The findings also concur with the works of Monyane and Emuze [9] and that of Brauers et al. [49] whose works found out that the most popular criteria considered by project owners during the bidding process were the assessment of managerial and the technical capabilities of a contractor. Furthermore, the findings are in tandem with the works of Plebankiewiez [23], Watt et al. [2] and Al-Gobali [48] wherein their respective studies, it became evident that health and safety records were found to be one of the prequalification criteria commonly used to identify a capable contractor for a given project. Selecting contractors with good safety record have a direct bearing on reducing cases of accidents as well as saving construction costs on the project site.

\subsection{Multi-Criteria Selection Methods}

This section of the paper identifies the other multi-criteria selection methods that are used to supplement the application of the prequalification selection criteria within the construction industry. Respondents' ratings on the multi-criteria selection methods used within the Ghanaian context have been presented in $\mathrm{Ta}$ ble 4. The respondents rated their familiarity with the methods using a 4-point Likert scale. A significant level of 0.05 was pre-determined and a hypothesize mean of 2.5 was chosen as an indicator of rating the respondents' familiarity with the contractor selection criteria. The result shows that "Program Evaluation and Review Technique (PERT) approach" and "Analytic Network Process

Table 4. Multi-criteria selection criteria.

\begin{tabular}{|c|c|c|c|c|c|c|}
\hline \multirow{2}{*}{ Selection Criteria } & \multicolumn{2}{|c|}{ Descriptive } & \multicolumn{3}{|c|}{ One-sample t-test } & \multirow{2}{*}{ Remark } \\
\hline & Mean & Std. Dev. & t & Mean Difference & Sig. (2-tailed) & \\
\hline Multi-Criteria Utility Theory (MUT) & 2.43 & 0.498 & -10.699 & -0.568 & 0.00 & Not familiar \\
\hline Complex Proportional Assessment (COPRAS) & 2.03 & 0.734 & -12.341 & -0.966 & 0.00 & Not familiar \\
\hline Evidential Reasoning (ER) & 2.27 & 0.840 & -8.117 & -0.727 & 0.00 & Not familiar \\
\hline Analytic Network Process (ANP) & 2.78 & 0.823 & -2.462 & -0.216 & 0.00 & Familiar \\
\hline Program Evaluation and Review Technique (PERT) & 2.93 & 0.755 & -0.847 & -0.068 & 0.00 & Familiar \\
\hline Fuzzy Set Theory (FST) & 1.76 & 0.479 & -24.241 & -1.239 & 0.00 & Not familiar \\
\hline
\end{tabular}

Sig. $\leq$ 0.05; Mean 1.0 to $1.44=$ not at all familiar; Mean 1.50 to $2.44=$ not familiar; Mean 2.5 to $3.44=$ familiar; Mean 3.44 to $4.0=$ very familiar. 
(ANP)" were rated by the respondents above the hypothesize mean with mean values of 2.93 and 2.78, respectively. "Multi-criteria utility theory (MUT)" and "Evidential Reasoning (ER)" were the next items rated with mean values of 2.43 and 2.27, respectively, whiles "Complex Proportional Assessment (COPRAS)", "Fuzzy Set Theory (FST)" had mean values of 2.03 and 1.76 respectively, were all below the hypothesize mean. With the exception of PERT and ANP approaches which the respondents rated familiar, all the other approaches were rated as not familiar. The one sample t-test analysis conducted recorded values that were all less than 0.05 which indicate that the respondents' ratings were significant.

The findings from this study are consistent with the findings of Pohekar and Ramachandran [49] which reported that MUT was not familiar among consultants or decision makers for the selection of contractors for a given project. The MUT less familiarity among Ghanaian contractors and consultants came as no surprise since Pohekar and Ramachandran [50] attributed its less applicability and familiarity to the requirements of interactive decision environment required when formulating utility functions and the ambiguity of computing the scaling constants using the algorithm. Another reason that could have accounted for its less familiarity among Ghanaian contractors and consultants is the difficulty attached to its application since it places an enormous burden on the client or decision maker, as it demands that the user ask a large number of hypothetical, lottery-type questions in order to discover their real preferences [21]. The findings are in disagreement to the earlier works of Sönmez et al. [51] and Yen [52] which identified ER as one of the generally used decision-making tool employed by consultants and decision makers when deciding on which contractor to select for a construction project. The result further indicates that respondents were not familiar with the application of FST approach by Ghanaian decision makers when selecting contractors for a construction project, which is inconsistent with the findings of Nieto-Morote and Ruz-Vila [36] that FST is one of the widely employed selection methods in the advanced economies.

The current study's findings corroborate the works of Yilmaz and Ergonul [53] and Mohantry et al. [54] which identified ANP as one of the selection methods that are very familiar among consultants and decision makers. With the application PERT in selecting contractors, results from this study revealed that the respondents were equally familiar with its usage within the Ghanaian construction industry. As posited by Aribisala et al. [55], ever since its inception, PERT has been regarded as a very useful decision-making tool in the field of manufacturing, governance, construction, research management, product development and information technology. Chinneck [56] identified PERT as one of the commonly applied decision-making tools within the construction industry.

\subsection{Benefits of Contractor Selection Criteria}

This section provides the result of the benefits of contractor selection criteria 
used within the Ghanaian construction industry. The respondents rated the benefits of the contractor selection criteria with a 5-point Likert scale. A significant level of 0.05 was used and a hypothesize mean of 3.5 was chosen as an indicator of rating the respondents' agreement to the benefits of the contractor selection criteria.

From Table 5, it can be seen that "enable the client or project owner to select contractors who are performers for the project" was rated the highest with mean values of 4.43. The other items that were agreed by the respondents as benefits of the contractor selection criteria are "save the project owner a lot of time", "minimize the possibility of contractor default" and "facilitate the achievement of project success and the objectives within the scheduled time" with mean values $4.00,3.94$ and 3.8, respectively. The respondents rated "maximize overall value to the project owner or client" as neutral with mean value 3.24 , and disagreed that "reducing all the associated project risk during the bidding and the construction processes" is a benefit of the contractor selection criteria. With the exception of "save the project owner a lot of time" and "minimize the possibility of contractor default" which recorded values greater than 0.05 , all the other items rating was found to be significant.

The findings of this study are in line with the result of Ogunsemi and Aje [28] study which revealed that the application of prequalification contractor selection method led to massive project success in Nigeria. The ability of the identified contractor selection criteria to facilitate project success and objectives within their scheduled time could be linked to the reasons given by Nwachukwu [22] and Plebankiewiez [23] that prequalification contractor selection criteria enable project owners to screen the list of contractors and shortlist the possible contractors who may have the ability to undertake the project. The result from this study is in disagreement with the findings of Darvish et al. [31], which identified

Table 5. Benefits of contractor selection criteria.

\begin{tabular}{|c|c|c|c|c|c|c|}
\hline \multirow{2}{*}{ Benefits } & \multicolumn{2}{|c|}{ Descriptive } & \multicolumn{3}{|c|}{ One-sample t-test } & \multirow{2}{*}{ Remark } \\
\hline & Mean & Std. Dev. & $\mathrm{t}$ & Mean Diff. & Sig. (2-tailed) & \\
\hline $\begin{array}{l}\text { Facilitate the achievement of project success and the objectives } \\
\text { within the scheduled time }\end{array}$ & 3.81 & 1.303 & -1.391 & -0.193 & 0.168 & Agree \\
\hline $\begin{array}{l}\text { Reduce all the associated project risk during the bidding and } \\
\text { the construction processes }\end{array}$ & 2.49 & 1.135 & -12.496 & -1.511 & 0.00 & Disagree \\
\hline Maximize overall value to the project owner or client & 3.24 & 1.304 & -5.476 & -0.761 & 0.00 & Neutral \\
\hline $\begin{array}{l}\text { Enable the client or project owner to select contractors who } \\
\text { are performers for the project }\end{array}$ & 4.43 & 0.498 & 8.131 & 0.432 & 0.00 & Agree \\
\hline Minimize the possibility of contractor default & 3.94 & 1.207 & -0.442 & -0.057 & 0.66 & Agree \\
\hline Save the project owner a lot of time & 4.00 & 0.773 & 0.00 & 0.00 & 1.00 & Agree \\
\hline
\end{tabular}

Sig. $\leq$ 0.05; Mean 1.0 to $1.4=$ strongly disagree; Mean 1.5 to $2.4=$ disagree; Mean 2.5 to $3.4=$ neutral; Mean 3.5 to $4.4=$ agree; Mean 4.5 to $5.0=$ strongly agree. 
that contractor selection criteria helped project owners to reduce the opportunity of contractor default in bidding and restrict the number of eligible contractors involved. It was also found that the respondents were indecisive on whether the contractor selection criteria maximize overall value to the project owner or client, which contradicts the findings by Huang [29] and Al-Harbi [30] that through the application of contractor selection criteria, project owners were able to ensure successful and efficient use of their money. The results also revealed that the contractor selection methods employed in Ghana have enabled both client and project owners to select contractors who are performers for the project, which is in agreement with Olatunji [24] that through prequalification selection methods, projects owners within Nigeria were able to select high performing contractors for a given project.

\subsection{Challenges Associated with Contractor Selection Criteria}

Table 6 presents the respondents' responses on the extent to which the challenges attributed to the contractor selection criteria in Ghana based on a 3-point Likert scale. The result shows that "excessive cost and time overrun" had the highest mean value of 2.51 with 0.00 significant level suggests to a "high extent" the challenge to the contractor selection criteria in Ghanaian context. This result affirms the results of Nkanta et al. [34] which observed that application of prequalification criteria for contractor selection often leads to time and cost overruns due to the wrong selection of a contractor. Nkanta et al. [34] linked this occurrence to the fact that most of the prequalification criteria are informed from information provided by the contractor as well as additional evidence given on paper records. However, the weakness with this approach is that due to the limited time required to assess bidders' documents, project owners usually do not have the time and resources to confirm the state of some of the claims

Table 6. Challenges associated with the contractor selection criteria.

\begin{tabular}{|c|c|c|c|c|c|c|}
\hline \multirow[b]{2}{*}{ Challenges } & \multicolumn{2}{|c|}{ Descriptive } & \multicolumn{3}{|c|}{ One-sample t-test } & \multirow{2}{*}{ Remark } \\
\hline & Mean & Std. Dev. & $\mathbf{t}$ & Mean Diff. & Sig. (2-tailed) & \\
\hline It leads to projects failure in terms of time delay & 1.59 & 0.90 & -4.24 & -0.409 & 0.00 & Medium extent \\
\hline Poor quality standard & 2.23 & 0.96 & 2.20 & 0.227 & 0.03 & Medium extent \\
\hline $\begin{array}{l}\text { Some of the criteria are very complex and difficult to } \\
\text { apply in practice }\end{array}$ & 2.20 & 0.68 & 2.81 & 0.205 & 0.01 & Medium extent \\
\hline Excessive cost and time overrun & 2.51 & 0.56 & 8.45 & 0.511 & 0.00 & High extent \\
\hline Substandard work & 1.67 & 0.88 & -3.51 & -0.33 & 0.00 & Medium extent \\
\hline Imprecise assessments due to lack of information & 2.22 & 0.78 & 2.59 & 0.216 & 0.01 & Medium extent \\
\hline Shortcomings in expertise in the methods application & 1.74 & 0.46 & -5.24 & -0.261 & 0.00 & Medium extent \\
\hline Disputes among contractors and clients & 1.69 & 0.53 & -5.40 & -0.307 & 0.00 & Medium extent \\
\hline
\end{tabular}

Sig. S 0.05; Mean 1.0 to $1.44=$ low extent; Mean 1.50 to $2.44=$ medium extent; Mean 2.5 to $3.0=$ high extent. 
made or presented by a contractor hence resulting to the selection of incompetent contractors at the end.

Conversely, "removal of effective and competent contractors" recorded the lowest mean value of 1.31 with 0.00 significant level, indicating a "low extent" rating by respondents on the challenge to the contractor selection criteria. In terms of intensity of this challenge, the respondents held that to a low extent this challenge can be attributed to the application of the identified prequalification criteria. Findings from this study affirm the view expressed by Olatunji [24] that adhering to strict prequalification criteria could lead to the removal of competent contractors from the bidding process. According to Olatunji [24], one of the key challenges associated with this kind of requirement or practice is that, at most often times contractors with excellent performance records are found not to have impressive scores during assessments, largely because most candidates do not have a good understanding about how to present their evidence or records in the required format. This suggests that an improper presentation of evidence to substantiate a contractor credibility during the assessment process is likely to make a capable contractor appear incompetent hence leading to his removal from the selection process.

Most of the respondents rated the other items (poor quality standard, imprecise assessments due to lack of information, some of the criteria are very complex and difficult to apply in practice, shortcomings in expertise in the methods of application, disputes among contractors and clients, substandard work, and it leads to projects failure in terms of time delay) with mean values between 2.23 and 1.59, indicating "medium extent" on the challenge to the contractor selection criteria. Findings of this study concur with the views of Nieto-Morote and Ruz-Vila [36] which observed that most of the contractor prequalification selection criteria are characterized in uncertainties and incomplete compilation of information hence, it makes it very difficult to establish the validity and objectiveness of its decision outcomes. Views expressed by the respondents are in tandem with the position of Ramezaniyana et al. [57] who argued that prequalification selection methods are usually based on the assumption that information on tenders exists during the decision making the process of the client. Furthermore, the findings from this study affirm the work of Rikhtegar [38] which asserts that another difficulty associated with multi-criteria selection method is that most of the tools are not able to handle the imprecise and ambiguous detail involved in real-life decision-making problems. Again, the findings concur with the studies of Yilmaz and Ergonul [53] which posited that although multi-criteria selection methods can improve the contractor selection process, nonetheless, one of the key challenges associated with its usage is that it is very complex and difficult to apply in practice.

\section{Implications of the Study}

This study contributes to the general body of knowledge in construction man- 
agement, specifically in the contractor selection for construction projects. It identified the prequalification selection criteria, multi-criteria selection methods, benefits and challenges of contractor selection in the Ghanaian construction industry. The results of this study are expected to assist construction professionals and researchers to focus on how to improve the contractor selection process order to ensure that qualified and competent contractors are selected to execute construction project to maximize the full benefits while reducing the associated challenges. The implications of this study are not limited to construction professionals and researchers alone. Findings of this study could also help the Government of Ghana to introduce policies and measures that will curb the challenges that are associated with the contractor selection criteria in Ghana. It is obvious from the results that the construction professionals are not familiar with multi-criterial section methods, therefore, it is expected of government to come out with measures that will equip the construction professionals with knowledge and skills in applying the multi-criterial section methods during contractor selection process.

\section{Summary and Conclusions}

The study investigated the contractor selection criteria in the Ghanaian construction industry, considering the benefits and challenges. Based on the findings of the study, the following concluding summary is provided:

- The prequalification selection methods familiar with the respondents include: management and technical ability evaluation method, the contractor's experience evaluation method, the contractor's past performance method, health and safety, and environmental measures method. This clearly indicates that the construction professionals are well vested with the prequalification selection criteria that are being employed or used within the Ghanaian construction industry.

- The respondents indicated their unfamiliarity with the following multi-criterial section methods: multi-criteria utility theory (MUT), complex proportional assessment (COPRAS), evidential reasoning (ER), and fuzzy set theory (FST). This suggests that the construction professionals are not familiar with multi-criterial section methods.

- It was also found that: enabling the client or project owner to select contractors who are performers for the project, saving the project owner a lot of time, minimizing the possibility of contractor default, and facilitating the achievement of project success and the objectives within the scheduled time, are the benefits of the contractor selection criteria in the Ghanaian construction industry.

- Excessive cost and time overrun, poor quality standard, imprecise assessments due to lack of information, the criteria being very complex and difficult to apply in practice, shortcomings in expertise in the methods application, disputes among contractors and clients, substandard work, and projects 
failure in terms of time delay, were identified as the challenges to the contractor selection criteria.

The study, therefore, recommends to the construction professionals to take the necessary measures to reduce the identified challenges, and also abreast themselves with the multi-criteria selection methods in order to help select qualifies and competent contractors. Furthermore, the study recommends for further studies to determine the impact of the identified challenges on construction projects, and ways to minimize the impact.

\section{Conflicts of Interest}

The authors declare no conflicts of interest regarding the publication of this paper.

\section{References}

[1] Bochenek, J. (2014) The Contractor Selection Criteria in Open and Restricted Procedures in the Public Sector in Selected EU Countries. Proceedings of the Creative Construction Conference, Prague, 21-24 June 2014.

[2] Watt, D., Kayis, B. and Willy, K. (2010) The Relative Importance of Tender Evaluation and Contractor Selection Criteria. International Journal of Project Management, 28, 51-60. https://doi.org/10.1016/j.ijproman.2009.04.003

[3] Khan, S. and Al-Hosany. A. (2016) Multi-Million Construction Contractor Selection: A Comparative Study. International Journal of Intelligent Enterprise, 3, 93-119. https://doi.org/10.1504/IJIE.2016.076030

[4] Salama, M., Aziz, H., El Sawah, H. and El Samadony, A. (2006) Investigating the Criteria for Contractors' Selection and Bid Evaluation in Egypt. In: Boyd, D., Ed., Procedure of 22nd Annual ARCOM Conference, Birmingham, 4-6 September 2006, Association of Researchers in Construction Management, Birmingham, 531-540.

[5] Kog, F. and Yaman, H. (2014) A Meta Classification and Analysis of Contractor Selection and Prequalification. Procedia Engineering, 85, 302-310.

https://doi.org/10.1016/j.proeng.2014.10.555

[6] Pinamang, P.A., Adu Gyamfi, T., Danso, H. and Ampofo Kwame, J. (2018) Schedule Delay Analysis of Construction Projects in Ghana: Objectives, Importance and Effects. Civil and Environmental Research, 10, 25-30.

[7] Enyinda, C., Ogbuehi, A. and Udo, G. (2011) A Decision Support Model for Contractor Selection in a Government Procurement Supply Chain: Evidence from an Emerging Market. Journal of Management Policy and Practice, 12, 9-17.

[8] Skibniewski, M. and Chao, L. (1992) Evaluation of Advanced Construction Technology with the AHP Method. Journal of Construction Engineering and Management, ASCE, 118, 255-261. https://doi.org/10.1061/(ASCE)0733-9364(1992)118:3(577)

[9] Monyane, T. and Emuze, F. (2015) Exploring Contractor Selection Process for Public Sector Projects in South Africa. A Provincial Case Conference, Paper 011.

[10] Gyadu-Asiedu, W., Danso, H. and Asubonteng, J.A. (2013) Assessment of the Performance of Local and Foreign Road Construction Firms in Ghana. The International Journal of Construction Management, 13, 53-73. https://doi.org/10.1080/15623599.2013.10878229 
[11] Topcu, Y. (2004) A Decision Model Proposal for Construction Contractor Selection in Turkey. Building and Environment, 39, 469-481. https://doi.org/10.1016/j.buildenv.2003.09.009

[12] El-Sawalhi, N., Eaton, D. and Rustom, R. (2007) Contractor Pre-Qualification Model: State-of-the-Art. International Journal of Project Management, 25, 465-474. https://doi.org/10.1016/j.ijproman.2006.11.011

[13] Alemu, A.D. (2015) Assessment of Contractors' Qualification Criteria in Ethiopia Federal Road Project Tender Practices. Master's Thesis, Addis Ababa University, Addis Ababa.

[14] Singh, D. and Tiong, R.L.K. (2006) Contractor Selection Criteria: Investigation of Opinions of Singapore Construction Practitioners. Journal of Construction Engineering and Management, 132, 998-1008.

https://doi.org/10.1061/(ASCE)0733-9364(2006)132:9(998)

[15] Zavadskas, E.K., Turskis, Z. and Tamošaitienè, J. (2008) Contractor Selection of Construction in a Competitive Environment. Journal of Business Economics and Management, 9, 181-187. https://doi.org/10.3846/1611-1699.2008.9.181-187

[16] Awad, A. and Fayek, A. (2012) A Decision Support System for Contractor Prequalification for Surety Bonding. Automation in Construction, 21, 89-98.

https://doi.org/10.1016/j.autcon.2011.05.017

[17] Ramón, J. and Cristóbal, S. (2012) Contractor Selection Using Multicriteria Decision-Making Methods. Journal of Construction Engineering and Management, 138, 751-758. https://doi.org/10.1061/(ASCE)CO.1943-7862.0000488

[18] Huang, S. and Keskar, H. (2007) Comprehensive and Configurable Metrics for Supplier Selection. International Journal of Production Economics, 105, 510-123. https://doi.org/10.1016/j.ijpe.2006.04.020

[19] Alarcon, L.F. and Mourgues, C. (2002) Performance Modeling for Contractor Selection. Journal of Management in Engineering, 18, 52-60. https://doi.org/10.1061/(ASCE)0742-597X(2002)18:2(52)

[20] Hatush, Z. and Skitmore, M. (1997) Criteria for Contractor Selection. Construction Management and Economics, 15, 19-38. https://doi.org/10.1080/014461997373088

[21] Elsayah, O. (2016) A Framework for Improvement of Contractor Selection Procedures on Major Construction Project in Libya. Doctoral Thesis, School of Engineering and the Built Environment, Edinburgh Napier University, Edinburgh.

[22] Nwachukwu, G. (2006) Selection of Consultants and Contractors under Due Process. 35th Annual Conference of NIOB, Aba, 5-7 October 2006.

[23] Plebankiewiez, E. (2009) Contractor Prequalification Model Using Fuzzy Sets. Construction Engineering and Management, 15, 377-383.

[24] Olatunji, O. (2006) Procurement of Construction and Reconstruction Projects in the International Context-Due Process and Contractor Selection for Public Works in Nigeria. University of Newcastle, Newcastle.

[25] Morote, A.N. and Vila, F.R. (2012) A Fuzzy Multi-Criteria Decision-Making Model for Construction Contractor Prequalification. Automation in Construction, 1, 8-19. https://doi.org/10.1016/j.autcon.2012.04.004

[26] Ramani, J. (2000) Reducing the Bias in Contractor Prequalification Using Data Envelopment Analysis (DEA). M.Sc., the Project, Department of Civil Engineering, University of Toronto, Toronto.

[27] Holt, G.D., Olomolaiye, P. and Harris, F.C. (1994) Factor Influencing UK Construction Client' Choice of Contractor. Building and Environment, 29, 241-248. 
https://doi.org/10.1016/0360-1323(94)90074-4

[28] Ogunsemi, D.R. and Aje, I.O. (2006) A Model for Contractors' Selection in Nigeria. Journal of Financial Management of Property and Construction, 11, 33-43. https://doi.org/10.1108/13664380680001078

[29] Huang, X. (2011) An Analysis of the Selection of Project Contractor in the Construction Management Process. International Journal of Business and Management, 6, 184-189. https://doi.org/10.5539/ijbm.v6n3p184

[30] Al-Harbi, K.M. (2001) Application of the AHP in Project Management. International Journal of Project Management, 1, 19-27. https://doi.org/10.1016/S0263-7863(99)00038-1

[31] Darvish, M., Yasaei, M. and Saeedi, A. (2009) Application of the Graph Theory and Matrix Methods to Contractor Ranking. International Journal of Project Management, 1, 610-619. https://doi.org/10.1016/j.ijproman.2008.10.004

[32] Bendana, R., Cano, A. and Cruz, M. (2008) Contractor Selection: Fuzzy-Control Approach. Canadian Journal of Civil Engineering, 35, 473-486.

https://doi.org/10.1139/L07-127

[33] Fong, P.S. and Choi, S.K. (2000) Final Contractor Selection Using the Analytical Hierarchy Process. Construction Management and Economics, 18, 547-557. https://doi.org/10.1080/014461900407356

[34] Nkanta, S., Akpanebu, I. and Udoka, I. (2017) Determinants of Contractors' Pre-Qualification Criteria in a Recessed Economy Nigeria. International Journal of Advanced Studies in Business Strategies and Management, 5, 67-86.

[35] Danso, H. and Antwi, J.K. (2012) Evaluation of the Factors Influencing Time and Cost Overruns in Telecom Tower Construction in Ghana. Civil and Environmental Research, 2, 15-24.

[36] Nieto-Morote, A. and Ruz-Vila, F. (2012) A Fuzzy Multi-Criteria Decision Making Model for Construction Contractor Prequalification. Automation in Construction, 25, 8-19. https://doi.org/10.1016/j.autcon.2012.04.004

[37] Mahdi, I.M., Riley, M.J., Ferig, S.M. and Alexa, A.P. (2002) A Multi-Criteria Approach to Contractor Selection. Engineering Construction and Architectural Management, 9, 29-37.

[38] Rikhtegar, N. (2014) Environmental Impact Assessment Based on Group Decision-Making Environmental Impact Assessment Based on Group Decision-Making. Economic Research, 27, 378-392.

[39] Podvezko, V. (2011) The Comparative Analysis of MCDA Methods. Engineering Economics, 22, 134-146. https://doi.org/10.5755/j01.ee.22.2.310

[40] Ghauri, P. and Gronhaug, K. (2002) Business Research Methods in Business Studies: A Practical Guide. 2nd Edition, Prentice Hall, Sydney.

[41] Krejcie, R.V. and Morgan, D.W. (1970) Determining Sample Size for Research Activities. Educational and Psychological Measurement, 30, 607-610. https://doi.org/10.1177/001316447003000308

[42] Ahadzie, D.K. (2007) A Model for Predicting the Performance of Project Managers in Mass House Building Projects. PhD Thesis, University of Wolverhampton, Wolverhampton.

[43] Laryea, S. and Mensah, S. (2010) The Evolution of Indigenous Contractors in Ghana. West Africa Built Environment Research Conference, Accra, 27-28 July 2010, 579-588.

[44] Saunders, M., Lewis, P. and Thornhill, A. (2009) Research Methods for Business 
Students. Pearson, New York.

[45] Straub, D.W., Boudreau, M.-C. and Gefen, D. (2004) Validation Guidelines for IS Positivist Research. Communications of the Association for Information Systems, 13, 380-427.

[46] Mugenda, O.M. and Mugenda, A.G. (2003) Research Methods, Quantitative and Qualitative Approaches. ACT, Nairobi.

[47] Ng, S. and Skitmore, M. (1999) Client and Consultant Perspectives of Prequalification Criteria. Building and Environment, 34, 607-621. https://doi.org/10.1016/S0360-1323(98)00050-X

[48] Al-Gobali, K.H. (1994) Factor Considered in Contractor Prequalification Process in Saudi Arabia. M.Sc. Project, University of Petroleum and Minerals, Dhahran.

[49] Brauers, W.K., Zavadskas, E.K., Turskis, Z. and Vilutienė, T. (2008) Multi-Objective Contractor's Ranking by Applying the MOORA Method. Journal of Business Economics and Management, 9, 244-255. https://doi.org/10.3846/1611-1699.2008.9.245-255

[50] Pohekar, S. and Ramachandran, M. (2004) Application of Multi-Criteria Decision Making to Sustainable Energy Planning-A Review. Renewable and Sustainable Energy Reviews, 8, 365-381. https://doi.org/10.1016/j.rser.2003.12.007

[51] Sönmez, M., Yang, J., Graham, G. and Holt, G. (2005) An Evidential Reasoning Based Decision-Making Process for Pre-Qualifying Construction Contractors. The Built Environment Research, University of Wolverhampton, Wolverhampton.

[52] Yen, J. (1990) Generalizing the Dempster-Shafer Theory to Fuzzy Sets. IEEE Transactions on Systems, Man, and Cybernetics, 20, 559-570. https://doi.org/10.1109/21.57269

[53] Yilmaz, A. and Ergonul, S. (2011) Selection of Contractors for Middle-Sized Projects in Turkey. Gazi University Journal of Science, 24, 477-485.

[54] Mohantry, R., Agarwal, R., Choudhury, A. and Tiwari, M. (2005) A Fuzzy ANP-Based Approach to R\&D Project Selection: A Case Study. International Journal of Production, 43, 5199-5216. https://doi.org/10.1080/00207540500219031

[55] Aribisala, A., Otenaike, A., Balogun, O. and Ofusori, L. (2017) Analysis of an Engineering Project Using Program Evaluation and Review Technique. Journal of Engineering and Technology, 2, 9-12.

[56] Chinneck, J. (2009) Practical Optimization, Chapter 11 in Practical Optimization: A Gentle Introduction, Carleton.

[57] Ramezaniyana, M., Kazemib, M., Jafarib, H. and Elahib, S. (2012) Application of Integrated Fuzzy VIKOR \& AHP Methodology to Contractor Ranking. Management Science Letters, 2, 1511-1526. https://doi.org/10.5267/j.msl.2012.05.017 